\title{
"HEXAL Model" How It Can Collaborate With Health Service Providers and Travel Medicine
}

\author{
Morteza Izadi ${ }^{1,2}$, Mohammadjavad Hoseinpourfard ${ }^{1,3^{*}}$, Zahra Farhangi $^{1,2}$, Ali Ayoubian $^{4}$ \\ ${ }^{1}$ International Travel Medicine Center of Iran, Tehran, Iran \\ ${ }^{2}$ Health Research Center, Baqiyatallah University of Medical Sciences, Tehran, Iran \\ ${ }^{3}$ Institute for Cognitive Science Studies, Tehran, Iran \\ ${ }^{4}$ Department of Health Services Management, Tehran North Branch, Islamic Azad University, Tehran, Iran \\ Corresponding Author: Mohammadjavad Hoseinpourfard, Ph.D., International Travel Medicine Center of Iran \\ (ITMCI), Southern Sheikhbahaei Street, Molasadra Avenue, Vanak Square, Tehran, Iran. Tel: +98-9370265689, \\ Email: hpf.javad@gmail.com
}

Received June 7, 2017; Accepted June 10, 2017; Online Published June 11, 2017

\begin{abstract}
Introduction: Nowadays the trend to travel abroad has extremely grown. This is while, paying attention to travelers' health is an incredibly important issue. Many organizations try their best to provide health services during travelers' trips. Meanwhile, the biggest and most effecting health care providers all around the world are hospitals. Regarding this fact, a theory has been presented to help these organizations coordinate and direct much more effectively in compared to the past. It is noticeable to mention that this theory can help health care providers to gain a more sustainable position in order to develop medical tourism in their centers. Methods: A theory has been presented in this research with different dimensions. The major aspects of this model have been designed according to the relationships which exist in families. These relationships include: parents, children and others. Each of these aspects have been divided into two segments which are female and male. These aspects play their roles in three different dimensions.

Results: According to the results this study, it can be mentioned that there are 6 relationships in regards to the HEXAL Model in health service providers. These relationships include mother, father, sister, brother, step sister and other relationships. It can be also said that each of these dimensions have different responsibilities in both health care providers and travel medicine.

Conclusion: By using this model, health service providers can collaborate much more effectively. As a result, medical tourists and even other tourists can experience much more satisfying trips throughout their lives.

Keywords: Hexal model, Health services, Travel medicine, Hospitals
\end{abstract}

Citation: Izadi M, Hoseinpourfard M, Farhangi Z, Ayoubian A. "HEXAL Model" How it can collaborate with health service providers and travel medicine. Int J Travel Med Glob Health. 2017;5(2):38-40. doi:10.15171/ijtmgh.2017.08.

\section{Introduction}

International medical travel (IMT), which is also known as medical tourism, has had many definitions throughout the past few years such as: "movements by persons from one country to another to obtain healthcare services." 1,2 The factors showing why people undertake IMT are often divided into push and pull factors. The push factors include the structural attributes between the "sending" and "receiving" countries, ${ }^{2}$ which include the costs of healthcare in their own country, ${ }^{3}$ avoiding waiting lists, ${ }^{4,5}$ escaping regulations and access to experimental or non-standard treatments. ${ }^{6}$ In contrast, the pull factors include the complicated motivations of individuals conditioned by cultural, linguistic and religious factors. ${ }^{7,8}$ Nowadays, the trend to travel internationally and abroad has increasingly grown. The development of air transportation has ensured that more than 700 million people currently travel internationally each year to every part of the world. ${ }^{9}$ Travel medicine which is also known as medical tourism, plays a tremendous role in the future of global medical care. ${ }^{10}$ Travel medicine tries to prevent illnesses and injuries occurring to travelers going abroad and manages problems arising in travelers coming back or coming from abroad. ${ }^{11}$ This is all due to the growth of technology, economy and other global relations. ${ }^{11}$ Globally speaking, medical tourism has become one of the fastest growing tourism sectors throughout the world with many countries strategically planning for their economic expansion. ${ }^{12}$ This significant growth in medical tourism has been facilitated by the rise of

Copyright $(2017$ The Author(s). This is an open access article distributed under the terms of the Creative Commons Attribution License (http:// creativecommons.org/licenses/by/4.0), which permits unrestricted use, distribution, and reproduction in any medium, provided the original work is properly cited. 
the internet and the emergence of healthcare intermediaries or medical tourism facilitators between international patients and hospital networks. ${ }^{13}$ Incredible advances in technology along with affordable travelling offers have significantly brought advantages to the global tourism industry. ${ }^{14}$ As seen in many parts of the world, medical tourism is resulting from the globalization of healthcare and tourism itself constituting extreme economic potential for the global economy. ${ }^{15,16}$ It is obvious that one of the most important sectors which are playing a tremendous role in medical tourism are the health care providers. ${ }^{17}$

The biggest and most effecting health care providers all around the world are hospitals. "A hospital is a health care institution, providing patient treatment with specialized staff and equipment." It is said that hospitals are one of the most critical organizations in every society. ${ }^{18}$

\section{Methods}

Regarding the above mentioned facts, a theory has been presented to help these organizations coordinate and direct much more effectively in compared to the past. It is noticeable to mention that this theory can help health care providers to gain a more sustainable position in order to develop medical tourism in their centers.

The dimensions of this theory include the mother, father, sister, brother, step sister and other relationship dimensions which are described as follows.

Mother: In this category, a bigger hospital exists which provides methods to other centers. The other centers are much smaller but provide similar services. It is actually said that the bigger hospital supports the other centers both for their human and financial resources.

Father: In this type of categorization, all the hospitals are the same. All of them have a main center which enables them at the same time. This center is a hyper or huge hospital which enables the others. This is while these centers do no support the other hospital as regards to their needed human resources and also their financial resources.

Sister: These centers do not have a role in each other's creation, but they play a role in enabling and especially in supporting.

Brother: These centers do not have a role in creation but do play a role in enabling each other. For example they help in education fields, exchanging lecturers and students. In the meanwhile, in case of the occurrence of bankruptcies in any center, the other centers are not responsible for supporting the specific center.

Step Sister: These centers help each other in limited areas. This collaboration is usually due to some similarities in these centers. For example, like when specific physicians are present

Table 1. HEXAL Model

\begin{tabular}{lccccccc}
\hline \multirow{2}{*}{ Role } & \multicolumn{5}{c}{ Condition } \\
\cline { 2 - 7 } & \multicolumn{2}{c}{ Parents } & \multicolumn{2}{c}{ Children } & \multicolumn{2}{c}{ Others } \\
\cline { 2 - 7 } & Father & Mother & Sister & Brother & Step-Sister & Other \\
\hline Creation & + & + & - & - & - & - \\
Enabling & + & + & + & + & - & - \\
Support & + & - & + & - & + & - \\
\hline
\end{tabular}

in two hospitals at the same time. The concentration in these kind of collaborations is basically support and it is said that this is due to the common sides that exist in organizations. These type of collaborations are made for further alliance and correlations.

In order for 2 cities to become step sisters, similarities are needed to be provided between them. For example, 2 historical cities, 2 scientific cities, 2 port cities and so on. The development of tourism in between 2 step sister cities and also naming the streets and roads of those cities from the other city is the result of naming 2 cities as step sisters. After the revolution, Tehran became the step sister of Bishkek, the capital of Kyrgyzstan for the first time.

Other relationships: Another type of relation is when organizations are neither involved in creation nor in support. These organizations have an extremely weak role of empowerment along with a much weaker role in supporting each other. For example, a medical team travel once a year from Germany to Iran for about a one-month period for different intentions and goals. Some of these intentions and goals have a financial base and the others have a charitable base.

\section{Results}

The major aspects of this model have been designed according to the relationships which exist in families. These relationships include parents, children and others. Each of these aspects have been divided into 2 segments which are female and male. These aspects play their roles in 3 different dimensions. As shown in the HEXAL model, these dimensions are: support, enabling and creation (Table 1). In this model, a parent is an organization which has main roles of creation and support in both the male and female gender, whereas the enabling dimension is only considered in the female segment.

\section{Discussion}

The Apollo Hospitals model is an Indian Healthcare Center Chain (HCC). It was first established in 1983 between India, Kuwait, Qatar, and Bangladesh. Hospital networks are the networks or groupware relations between the hospitals that work together in order to coordinate and deliver a broad spectrum of services to their community. These health care systems which are more than two hospitals owned, sponsored, or contract managed by a central organization. ${ }^{19}$

The Hannover-Tehran Hospitals is one of the samples of the Hexal Model definition which was established in the field of neuroscience by Professor Majid Samii. ${ }^{20}$

The Avicenna clinics are another example of the HCC models which has been introduced in the medical tourism field. These clinics could also be defined according to the Hexal Model..$^{5}$ Actually, it could be mentioned that the Hexal Model can help promote some aspects of HCC, especially in ethical values. ${ }^{20}$

By analyzing some health service center websites and their constructions, the HEXAL model can help develop and practice between them. ${ }^{21}$ Hence, the hospitals should design their websites according to a hierarchical construction because in order to avoid the confusion of patients. It also discusses the criteria of constructing outstanding hospital websites by hospital research bases according to knowledge 
management. ${ }^{22}$

\section{Conclusion}

While travelling, tourists may face several difficulties either physical or spiritual. It can be concluded that by using this model, health service providers can collaborate much more effectively. As a result, medical tourists and even other tourists can experience much more satisfying trips throughout their lives.

\section{Authors' Contributions}

All authors equally contributed throughout this research.

\section{Conflict of Interest Disclosures}

The authors have no conflicts of interest.

\section{Ethical Approval}

Not applicable.

\section{Funding/Support}

None.

\section{Acknowledgments}

The authors would like to thank the International Travel Medicine Center of Iran (ITMCI) for their great help and assistance during this study.

\section{References}

1. Whittaker A, Chee HL, Por HH. Regional circuits of international medical travel: prescriptions of trust, cultural affinity and history. Asia Pac Viewp. 2017. doi:10.1111/apv.12158.

2. Khan MJ, Chelliah S, Haron MS, Ahmed S. Push factors, risks, and types of visit intentions of international medical travelers-A conceptual model. Int J Healthc Manag. 2017;10(2):115-121. doi: 10.1080/20479700.2017.1304345.

3. Samadbeik M, Asadi H, Mohseni M, Takbiri A, Moosavi A, Garavand A. Designing a medical tourism website: a qualitative study. Iran J Public Health. 2017;46(2):249-257.

4. Connell J. Transnational health care: global markets and local marginalisation in medical tourism. In: Parry B, Greenhough B, Dyck I, eds. Bodies Across Borders: The Global Circulation of Body Parts, Medical Tourists and Professionals. Farnham: Ashgate; 2015:75-93.

5. Loh CPA. Trends and structural shifts in health tourism: Evidence from seasonal time-series data on health-related travel spending by Canada during 1970-2010. Soc Sci Med. 2015;132:173-180. doi:10.1016/j.socscimed.2015.03.036.

6. Moghavvemi S, Ormond M, Musa G, et al. Connecting with prospective medical tourists online: a cross-sectional analysis of private hospital websites promoting medical tourism in
India, Malaysia and Thailand. Tour Manag. 2017;58:154-163. doi:10.1016/j.tourman.2016.10.010.

7. Hoseinpourfard M, Ghanei M, Tofighi S, Ayoubian A, Izadi M. The emergence of Hajj stampedes: lessons for draw near in the Islamic values in Hajj Trauma centers accreditation. Trauma Mon. 2017; In Press. doi:10.5812/traumamon.39455.

8. Izad M, Hoseinpourfard M, Ayoubian A, Karbasi M, Jahangiri M, Jalali A. A Survey to the implementation of Islamic standards in the hospitals of Iran for attraction of muslim medical tourists. Int J Travel Med Glob Health. 2014;1(3):99-102.

9. Noree T, Hanefeld J, Smith R. Medical tourism in Thailand: a crosssectional study. Bull World Health Organiz. 2016;94(1):30-36.

10. Seow AN, Choong YO, Moorthy K, Chan LM. Intention to visit Malaysia for medical tourism using the antecedents of Theory of planned behaviour: a predictive model. International Journal of Tourism Research. 2017;19(3):383-393. doi:10.1002/jtr.2120.

11. Kangas B. Hope from abroad in the international medical travel of Yemeni patients. Anthropol Med. 2007;14(3):293-305.

12. Connell J, Fara X. Medical tourism in the Caribbean islands: a cure for economies in crisis. Island Stud J. 2013;8(1):115-130.

13. Glinos IA, Baeten R, Helble M, Maarse H. A typology of crossborder patient mobility. Health place. 2010;16(6):1145-1155.

14. Kasemsap K. Facilitating hospitality and tourism management in global business. In: Pappas N, Bregoli I, eds. Global Dynamics in Travel, Tourism, and Hospitality. Hershey: IGI Global; 2016:283305.

15. Aydin G, Karamehmet B. Factors affecting health tourism and international health-care facility choice. Int J Pharm Healthc Mark. 2017;11(1):16-36. doi:10.1108/IJPHM-05-2015-0018.

16. Ormond M, Sulianti D. More than medical tourism: lessons from Indonesia and Malaysia on South-South intra-regional medical travel. Current Issues in Tourism. 2017;20(1):94-110. doi:10.108 0/13683500.2014.937324.

17. Bolton S, Skountridaki L. The medical tourist and a political economy of care. Antipode. 2017;49(2):499-516. doi:10.1111/ anti.12273.

18. Pennings G. The ethical management of medical tourism. In: Botterill D, Pennings G, Mainil T, eds. Medical Tourism and Transnational Health Care. London, UK: Palgrave Macmillan; 2013:179-193.

19. American Hospital Association. Fast facts on US hospitals. http:// www.aha.org/research/rc/stat-studies/fast-facts.shtml. Accessed May 2014.

20. Izadi M, Ayoubian A, Hoseinpourfard M. Health tourism: a comprehensive guide for tourism policy makers, health managers, travel agencies, insurance and investors. Tehran: Baqiyatallah University of Medical Sciences; 2016.

21. Hoseinpourfard M, Ayoubian A. A Review on some active websites about Islamic lifestyle based on webometric criteria. Islamic Lifestyle Centered on Health. 2013;1(2):5-7. doi:10.5812/ ilch.9010.

22. Rafati H, Rashidi Jahan H, Pourfard MJH, Tavakoli HR, Tofighi S. Study about the pattern of knowledge management in (Glenview) healthcare service provider. World Appl Sci J. 2010;8(9):11161121. 